The next Cambridge SCCS will be on 22-24 March 2016, with plenary speakers Tom Brooks (IUCN), Taylor Ricketts (Gund Institute for Ecological Economics), Nancy Knowlton (Smithsonian National Museum of Natural History) and Mike Barry (Marks \& Spencer). Updates will be posted on the conference website (http://www.sccs-cam. org). There are now sister SCCS series in Australia, China, Hungary, India and the USA. Dates and application details are on the SCCS Cambridge website.

RHYS GREEN Department of Zoology, University of Cambridge, Downing Street, Cambridge CB2 3EJ, UK

E-mail reg29@cam.ac.uk

\section{The Whitley Awards 2015}

The annual Whitley Awards Ceremony was held on 29 April 2015 at the Royal Geographical Society in London. The flagship event of UK-based charity the Whitley Fund for Nature was hosted by wildlife presenter Kate Humble, and saw seven conservation leaders from six countries receive Whitley Awards worth GBP 35,000 each in project funding over 1 year in support of their work.

In addition, the prestigious Whitley Gold Award was presented to 2009 Whitley Award winner Dino Martins of Kenya for his efforts to conserve pollinators through sustainable farming practices. Over 400 people attended the event, where the charity's patron, HRH The Princess Royal, presented the Awards.

The 2015 Whitley Award Winners are: Arnaud Desbiez, Brazil (Giant armadillos as a flagship species for the conservation of tropical scrublands in the Cerrado); Rosamira Guillen, Colombia (Proyecto Tití: expanding conservation efforts to protect the cotton-top tamarin in northern Colombia); Panut Hadisiswoyo, Indonesia (Conservation villages: building local capacity for the protection of Sumatran orangutans and their habitat); Jayson Ibañez, Philippines (Preventing further decline of the Philippine eagle on Mindanao Island); Inaoyom Imong, Nigeria (Saving Cross River gorillas through community-based conservation in the Mbe Mountains); Ananda Kumar, India (Elephant messengers: using innovative communication systems to enable human-elephant coexistence in southern India); Pramod Patil, India (Community conservation of the great Indian bustard in the Thar Desert: a landscape-level approach).

For more information on the Whitley Fund for Nature and the Whitley Awards, and to view short films about each of the winning projects, see http://www.whitleyaward. org. See p. 564 for the call for applications for the 2016 Whitley Awards.

DANNI PARKS Whitley Fund for Nature, London, UK E-maildanni@whitleyaward.org 